\title{
Development and Performance Evaluation of a Vertical Farming Structure
}

\author{
K. K. Shaheemath Suhara ${ }^{1 *}$ and G. N. Priya ${ }^{2}$ \\ ${ }^{1}$ Department of Soil and Water Conservation Engineering, Tamil Nadu Agricultural \\ University, Coimbatore - 641003, India \\ ${ }^{2}$ Department of Soil and Water Conservation Engineering, Kerala Agricultural University, \\ Thrissur, Kerala, 680656, India \\ *Corresponding author
}

\begin{tabular}{|l|}
\hline Ke y w o r d s \\
Biometric \\
observation, Drip \\
irrigation, Light \\
intensity, \\
Temperature, \\
Vertical farming \\
\hline Article Info \\
\hline $\begin{array}{l}\text { Accepted: } \\
\text { 20 November } 2019 \\
\text { Available Online: } \\
\text { 10 December } 2019\end{array}$ \\
\hline
\end{tabular}

\section{A B S T R A C T}

The study was taken up to fabricate two vertical farming structures and to compare the crop performance under fabricated vertical farming structure I (FVFS I) and fabricated vertical farming structure II (FVFS II) in the Kelappaji college of agricultural engineering and technology (KCAET), Tavanur. The climatic parameters as well as biometric observations were noted for comparing the performance of plants under FVFS I and FVFS II. The analysis of these data suggested that adoption of FVFS I is advantageous than the FVFS II. The plant height, number of leaves, plant girth and yield varied between the two structures. The analysis of various data showed that the plants at the right side of the FVFS I had higher growth and yield than any other sides of FVFS I and FVFS II for the orientation in the east-west direction at that particular location. The study suggested that FVFS I can be recommended more precisely as a substitute to the conventional farming practices on limited or problematic land area.

\section{Introduction}

Modern day agriculture is a major contributor to a large range of environmental problems that the world is facing today like agricultural runoff, ecosystem degradation, use of fossil fuels, food wastage, under capacity drainage infrastructure etc. Studies reveal that nearly $80 \%$ of the earth's population will reside in urban areas by the year 2050. An estimated 109 hectares of new land is required to get enough food, if traditional farming practices continue as they are practiced today. At present scenario, over $80 \%$ of the land which is suitable for raising crops is in use, $20 \%$ of the land has been laid waste by poor management practices throughout the world (Despomier, 2010). 
Vertical farming as a component of urban agriculture is the practice of cultivating food within skyscrapers or on vertically inclined surfaces, where crops would be cultivated and grown inside multi-storey buildings that will imitate the ecological system. An abruptly growing global population and increasingly limited resources are making the technique of vertical farm more attractive than ever (Kalantari et al., 2018; Valley and Wittman, 2018). It will provide an alternative agricultural venue, allowing land that has been depleted to take a break and fix itself with natural growths. There is still a wide opportunity to go in constructing these vertical farms, since the aim is to generate more yields for every square feet of the system (Despommier, 2010). Vertical Farming has so many advantages like it may eliminate the need to generate additional farmlands and help to create a cleaner environment if it designed properly. Year-round crop production is also possible by this. There will not be any crop failure due to floods, pests, weeds and drought because vertical farming provides a controlled environment for crop growth. The productivity of vertical farms would be mostly independent of weather and protected from extreme weather events. Vertical farming eliminates the agricultural runoff and thereby increases the productivity of the agricultural crops. It can evade deforestation and desertification caused by agricultural encroachment on natural biomass (Omrani et al., 2017). In view of all the above facts this study has been undertaken to fabricate Vertical Farming Structures (VFS) suitable for homestead and to evaluate the performance of the fabricated vertical farming structures

\section{Materials and Methods}

\section{Location of study}

The experiment was conducted in KCAET, Tavanur, in Malappuram district, Kerala. The place is situated at the latitude of $10^{\circ} 52^{\prime} 30^{\prime \prime}$ North and $76^{\circ}$ East longitude. Major part of the rainfall in this region is contributed by south west monsoon. The area is having a relative humidity of about $80 \%$. The mean maximum temperature of the area is about $42.1^{\circ} \mathrm{C}$ and mean minimum temperature of the area is about $22^{\circ} \mathrm{C}$.

\section{Experimental setup}

The FVFS I has a dimension of $213 \mathrm{~cm} \times 163$ $\mathrm{cm} \times 213.3 \mathrm{~cm}$. It is a platform like structure consisting of three platforms on each side. Mild steel tubes and rods of different dimensions were used for making the frame and roof of the structure. Mild steel flats of $3 / 4$ " $\times 1 / 2$ " were used as a seating for grow bags. Thirty six grow bags of dimension of 15 $\mathrm{cm} \times 15 \mathrm{~cm}$ were placed in the frame. UV polythene sheets of 200 micron were used as a covering material for the roof. The seating for the grow bags were provided by fixing mild steel flats in between the square tubes. Each platform can accommodate six grow bags of size $15 \mathrm{~cm} \times 15 \mathrm{~cm}$ so that 36 grow bags can be placed in the FVFS 1 . The Figure 1 shows the FVFS 1 with specification.

The structure has a triangular cross section having base width $132 \mathrm{~cm}$ and height of 167 $\mathrm{cm}$. The height of the structure was fixed by considering the maximum possible reach of an average height person to harvest the crop. The FVFS 1 had two slanting faces of rectangular cross section having dimensions $183 \mathrm{~cm} \times 180$ $\mathrm{cm}$ each. Each platform having a width of 20.5 $\mathrm{cm}$ was enough for placing $15 \mathrm{~cm} \mathrm{x} 15 \mathrm{~cm}$ grow bags of 6 numbers. The height of each platform was designed according to the height of the structure and width of platform so that height of the first, second and third platform from top to bottom are $51 \mathrm{~cm}, 48 \mathrm{~cm}$ and 45 $\mathrm{cm}$ respectively. The roof has a Quonset shape made up of MS rods of 0.5 " diameter. The roof is supported by using mild steel rod of 
length $80 \mathrm{~cm}$ with the main structure in each corner. The UV sheet of 200 micron of 230 $\mathrm{cm} \times 180 \mathrm{~cm}$ was used for covering the roof. Three rings were connected on the roof by welding to place the PVC pipe for irrigation.

The FVFS II has rectangular cross section with over all dimension of $1.55 \mathrm{~m} \mathrm{x} 2.2 \mathrm{~m} \mathrm{x}$ $0.7 \mathrm{~m}$. The structure was fabricated using mild steel tubes and rods. Half splitted PVC piped of 6" diameter was used as a trough for growing crops. The structure is three tiers system which consists 19 half splitted PVC pipes. The FVFS II is shown in Figure 2. Half split PVC pipes of $2.80 \mathrm{~mm}$ wall thickness and $1.2 \mathrm{~m}$ length were provided in the middle rows. Half split PVC pipes of $50 \mathrm{~cm}$ length were provided in the side rows. The PVC splits were supported by semicircular rings made of $3 / 4$ " $\mathrm{x} 1 / 8$ " MS flat in each rows welded with the frame. To compare the FVFS I with FVFS II, the roof of the structure was covered by placing UV sheet of 200 micron of $1 \mathrm{~m} \mathrm{x}$ $2.6 \mathrm{~m}$.

The northern side of the ladies hostel premises, KCAET was selected for the installation of FVFS. The structure was oriented in the east-west direction. Six numbers of grow bags with $15 \mathrm{~cm} \mathrm{x} 15 \mathrm{~cm}$ size were placed in each platform of FVFS I.

The total number of plants was 72. In FVFS II, half split PVC pipes of six inch diameter were used for planting. The grow bags and PVC splits were filled with coco peat and soil in the ratio $1: 1$.

\section{Setup for irrigation}

The drip irrigation system was adopted to irrigate the plants to reduce the wastage of water. Main source of supply was water tank of ladies hostel, KCAET situated at a height of about $10 \mathrm{~m}$ from the ground level. The system was worked under gravity.

\section{Field Experiment}

The different tiers of the FVFS I and FVFS II were analyzed in this study and are given in the table 1 . There were 15 portions.

Seeds of variety 'anaswara' of cowpea was taken for the trial and seeds were directly placed in the grow bags as well as in the half split PVC pipes. The depth of rooting media in the half split PVC and grow bags was about $10 \mathrm{~cm}$. Two seeds were placed in each grow bag of FVFS I.

A total of 4 seeds were placed in each middle row and two seeds in side rows of the FVFS II. Irrigation was given daily by drip irrigation method at a rate of 1.5 litres per plant. The fertilizer was applied at the rate of 3 to $5 \mathrm{~g}$ per plant in a single dose in both the VFS.

Climatic parameters such as temperature and light intensity were observed in morning, afternoon and evening during the growth stage of the crop.

For analyzing the growth pattern of the crops, crops from each tier were selected randomly from each side of FVFS I and FVFS II.

Biometric observations such as plant height, girth and number of leaves were made once in a week. Harvesting was done after attaining maturity. The daily observations were tabulated and the average values of observations of each week were noted and were used for plotting the graphs.

\section{Results and Discussion}

Climatic parameters such as air temperature and light intensity were observed in the FVFS I and FVFS II. The daily observations were noted at 8:00 am, 1:30 pm and 5:00 pm for a period of three weeks from November to December 2016. 


\section{Air temperature}

The weekly average values for air temperature was calculated for 8:00 am, 1:30 pm and 5:00 $\mathrm{pm}$ from the daily data taken using thermometer and are shown in Figure 3. In Figure $3 \mathrm{a}$, it is clear that the maximum temperature measured in FVFS I was about $20.7{ }^{\circ} \mathrm{C}$ and in FVFS II about $20.6{ }^{\circ} \mathrm{C}$. Minimum temperature noted was $19.2{ }^{\circ} \mathrm{C}$ at FVFS I and $19.1{ }^{\circ} \mathrm{C}$ at FVFS II. There was only a small variation in air temperature in both the VFS at 8:00 am. The temperatures were almost the same in both structures.

A slight increase in air temperature inside FVFS I was observed compared to FVFS II during the noon hours and are shown in the figure $3 \mathrm{~b}$. The variation was more during the first week than in the second and third week. Maximum temperature noted in FVFS I was $24.3^{\circ} \mathrm{C}$ and in FVFS II was $24.2^{\circ} \mathrm{C}$. Minimum temperatures were $24^{\circ} \mathrm{C}$ and $23^{\circ} \mathrm{C}$ respectively. This may be due to the more reflected radiation from the ground surface to the FVFS I as there was a distance of $23 \mathrm{~cm}$ from the ground to the different tiers, which was lesser in FVFS II as it was about $10 \mathrm{~cm}$.

The figure $3 c$ describes that at evening, there was a small difference in temperature during the second week while it was almost the same in the first and third week. Maximum temperature in FVFS I was about $22.9^{\circ} \mathrm{C}$ and in FVFS II was $22.8^{\circ} \mathrm{C}$. Minimum temperatures were the same for both structures i.e., $22.4^{\circ} \mathrm{C}$. The temperature was almost same in 8:00 am, 1:30 pm and 5:00 pm in both FVFS I and FVFS II

\section{Light Intensity}

The weekly average values for light intensity was calculated for 8:00 am, 1:30 pm and 5:00 $\mathrm{pm}$ respectively from the daily observed data. Measurements were taken using lux meter in the range B. Observations were obtained from the three tiers of left and right hand side of the FVFS I. In FVFS II, the measurements were taken from the three tiers of left, middle and right sections.

Figure 4 shows the variations in light intensity of FVFS I and FVFS II at 8:00 am. The maximum light intensity was obtained from tier 3 (T3) at the right side of FVFS I. It was about 6657.1 lux. The minimum light intensity of 3984.2 lux was measured from tier 2 (T2) on the left side of FVFS I. The availability of solar radiation in the morning hours and reflected radiation obtained was observed maximum in tier 3 as it was close to the ground surface. In FVFS II, the maximum light intensity of 6580 lux was observed from the tier 2 (T2) at the left section and minimum of 2790 lux was observed from T3 at the middle section. Due to the orientation of the structure in east-west direction, in morning hours there was possibility of getting more solar radiation in left section of FVFS II as it was orienting towards east. The Figure 5 shows the variations in light intensity of FVFS I and FVFS II respectively at 1:30 pm. The maximum light intensity was obtained from tier 1 (T1) at the right side of FVFS I. It was about 12647 lux. The minimum light intensity of 5010 lux was observed from tier 2 (T2) on the left side of FVFS I. The tier 1 is the uppermost one and is close to the roof than other tiers, direct transmission of light is possible compared other tiers. The tier 2 (T2) is the middle one, there may be chance of less light intensity compared to tier1 (T1) and tier 3 (T3) as there is less availability of direct sunlight and reflected radiations. In FVFS II, the maximum light intensity of 11200 lux was measured from the tier 1 (T1) at the middle section and minimum of 3470 lux was measured from $\mathrm{T} 2$ at the middle section.

Figure 6 shows the variations in light intensity of FVFS I and FVFS II at 5:00 pm. The 
maximum light intensity was obtained from tier 1 (T1) at the right side of FVFS I. It was about 6674.2 lux. The minimum light intensity of 2150 lux was measured from tier 3 (T3) of left side of FVFS I. In FVFS II, the maximum light intensity of 5386 lux was measured from the tier 1 (T1) at the middle section and minimum of 1781 lux was measured from T3 at the middle section

The maximum light intensity was observed at tier T1 on the right hand side of FVFS I at 1:30 pm. From these observations, it was concluded that in the case of FVFS I, always the maximum light intensity was observed in tier 1 on the right hand side of the structure. This may be due to the location of the structures and the direction of reflected solar radiation. But in FVFS II, maximum light intensity was observed in the left section in morning hours, middle section in afternoon and right section in evening hours. This may be due to the orientation of the structure. Analysis of the Figure 4-6 shows the changes in light intensity between structures, in which higher light intensity was experienced in the FVFS I. This may be due to the structural difference between the structures as FVFS I is a platform like structure with triangular cross section where possibility of getting more light in each tier is higher. But in FVFS II, platforms are one over the other and thereby it may not be possible to get enough light compared to FVFS I due to the shade of platforms one over the other.

\section{Biometric observations}

\section{Plant Height}

The observations on height of the plants were taken in weekly interval. The height of selected plants from each tier was observed for three weeks. Maximum plant height at the end of $3^{\text {rd }}$ week was observed at tier T1 on right side of FVFS $\mathrm{I}$ and is about $68 \mathrm{~cm}$. Minimum plant height of $12 \mathrm{~cm}$ was found at the tier T1 on the right section of FVFS II. Plant heights in T1, T2, T3 on the left and right hand side of FVFS and left, middle and right sections of FVFS II were taken and plotted in a graph as shown in figure 7 . The growth of plants was more in FVFS than in FVFS II.

Table.1 The different tiers of the fabricated and existing VFS analyzed in this study

\begin{tabular}{|l|c|}
\hline FRT1 & top tier at right side of FVFS I \\
\hline FRT2 & middle tier at right side of FVFS I \\
\hline FRT3 & bottom tier at right side of FVFS I \\
\hline FLT1 & top tier at left side of FVFS I \\
\hline FLT2 & middle tier at left side of FVFS I \\
\hline FLT3 & bottom tier at left side of FVFS I \\
\hline ERTI & top tier at right section of FVFS II \\
\hline ERT2 & middle tier at right section of FVFS II \\
\hline ERT3 & bottom tier at right section of FVFS II \\
\hline EMT1 & top tier at middle section of FVFS II \\
\hline EMT2 & middle tier at middle section of FVFS II \\
\hline EMT3 & bottom tier at middle section of FVFS II \\
\hline ELT1 & top tier at left section of FVFS II \\
\hline ELT2 & middle tier at left section of FVFS II \\
\hline ELT3 & bottom tier at left section of FVFS II \\
\hline
\end{tabular}


Fig.1 Fabricated vertical farming structure I.

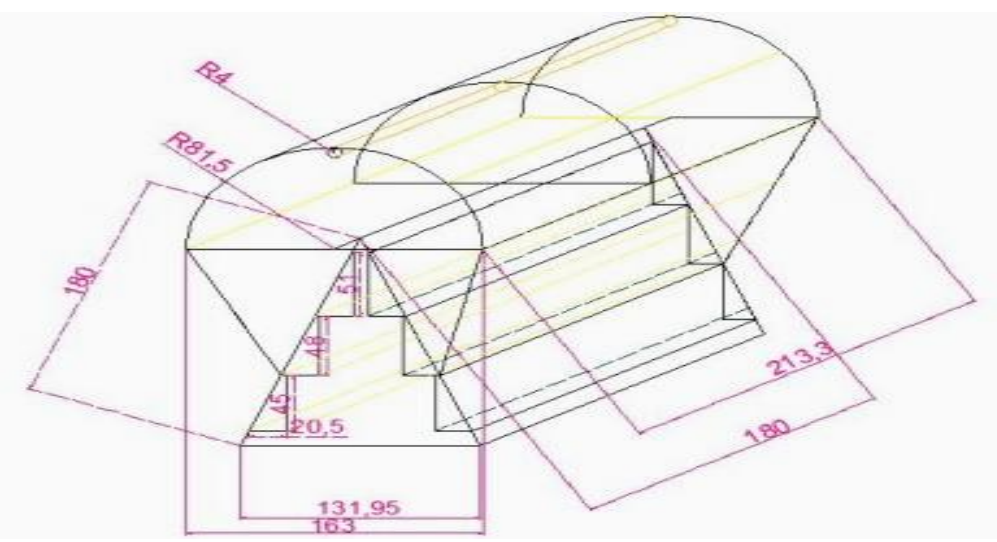

All in dimensions are in $\mathrm{cm}$

Fig.2 Fabricated vertical farming structure II

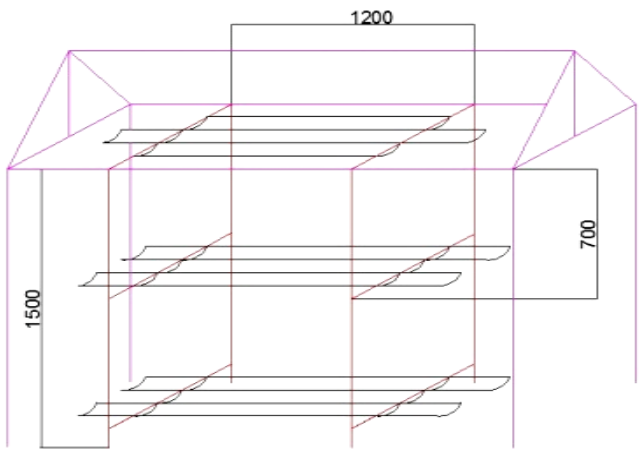

All dimensions are in $\mathrm{mm}$

Fig.3 Variation of air temperature in FVFS I and FVFS II at 8:00 am, 1:30 pm and 5:00pm

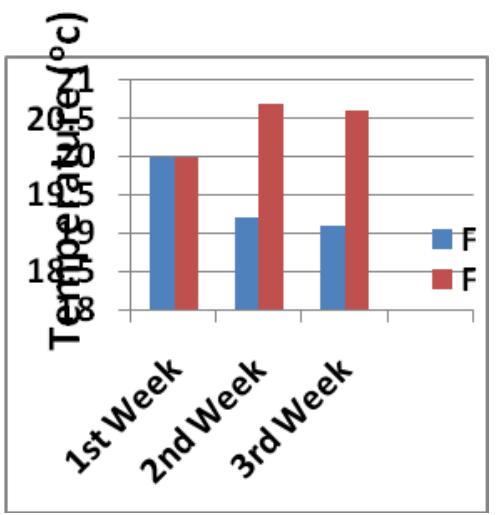

(a)

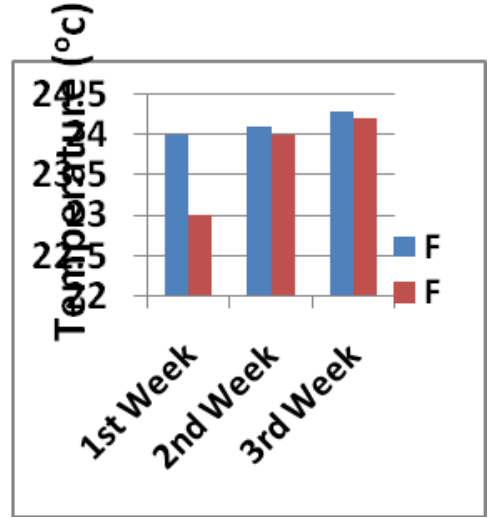

(b)

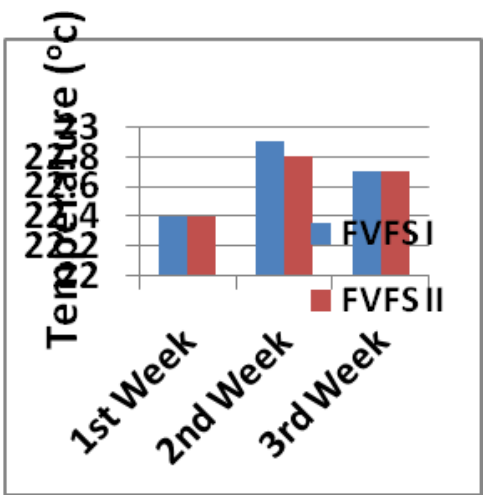

(c) 
Fig.4 Variation in light intensity of FVFS I and FVFS II respectively at 8.00 am

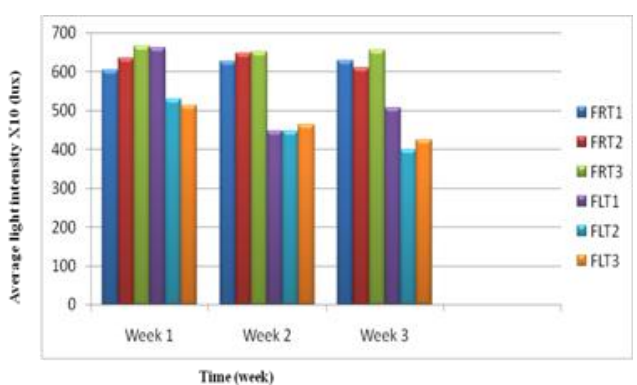

(a)

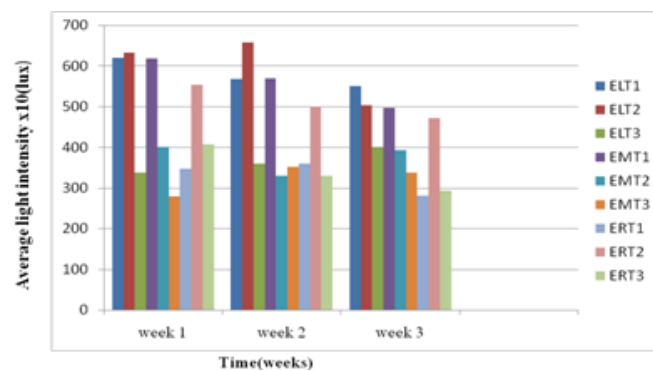

(b)

Fig.5 Variation in light intensity of FVFS I and FVFS II respectively at 1:30 pm
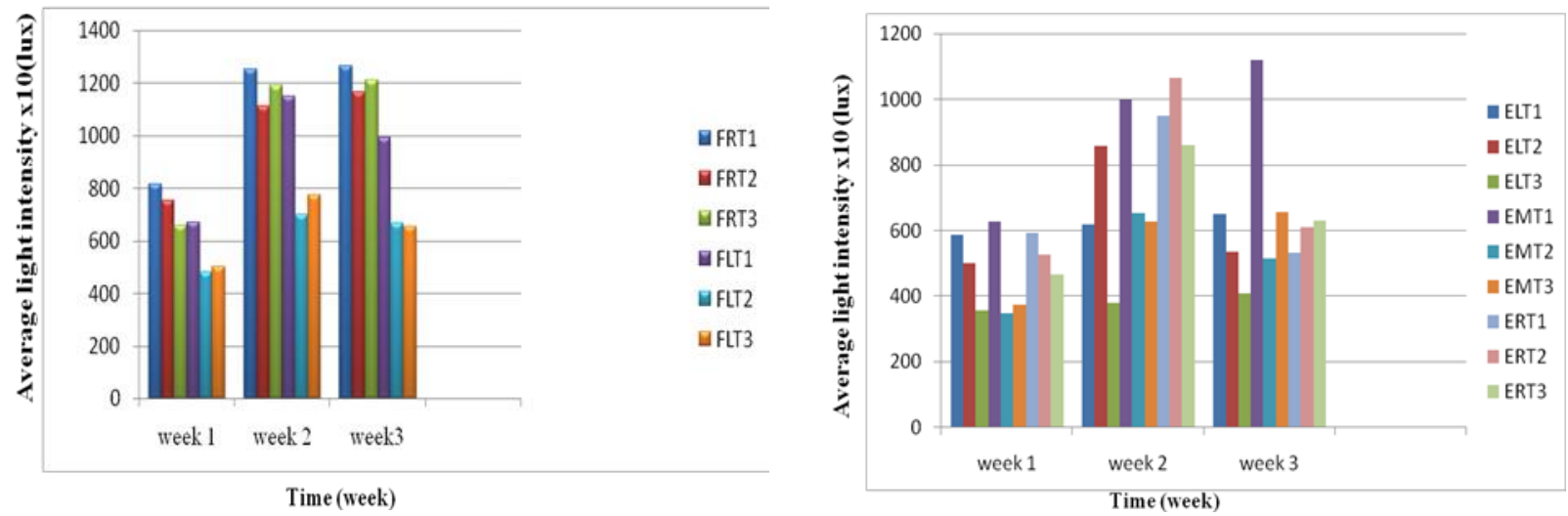

Fig.6 Variation of light intensity of FVFS I and FVFS II respectively at 5:00 pm
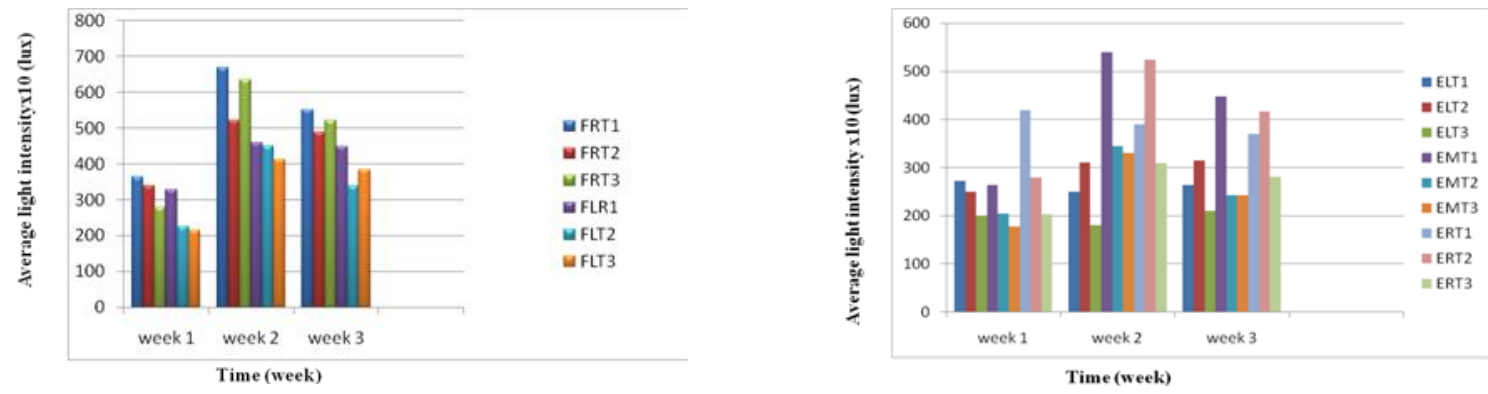

Fig.7 Variation of plant height in T1, T2 and T3 of FVFS I and FVFS II
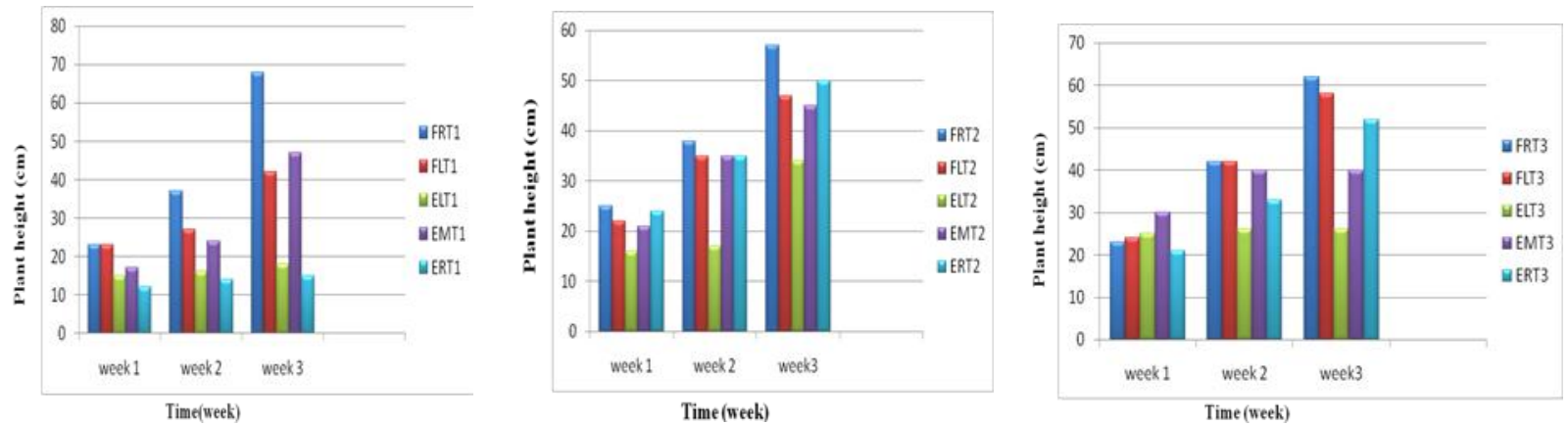
Fig.8 Variation of No. of leaves in T1, T2 and T3 of FVFS I and FVFS II
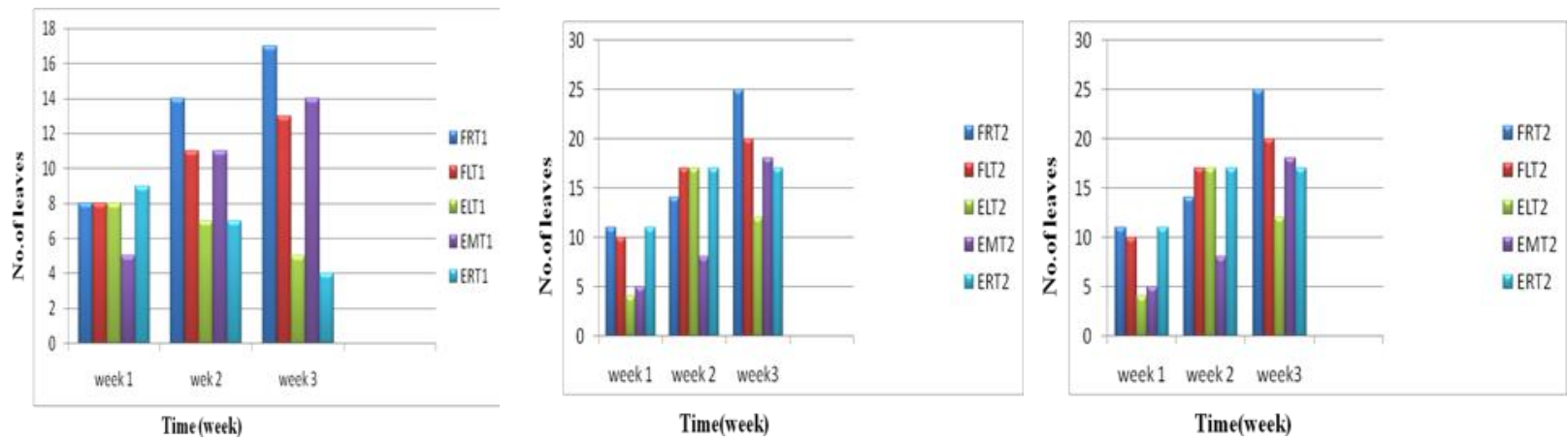

Fig.9 Variation of plant girth in T1, T2and T3 of FVFS I and FVFS II
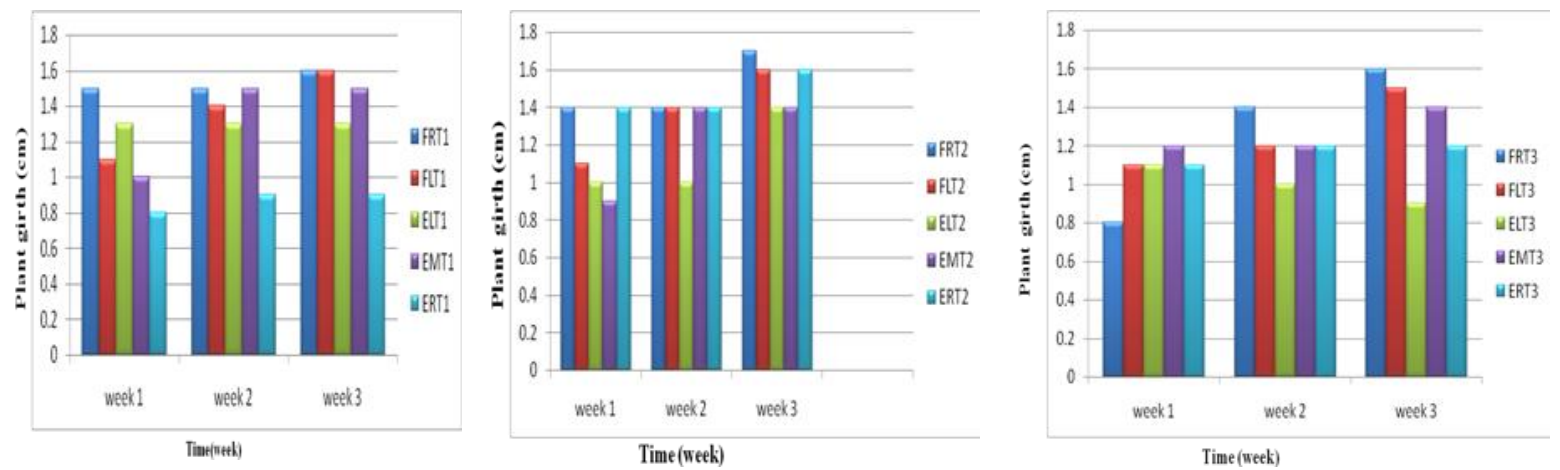

Considering tier $\mathrm{T} 1$ at the end of three weeks, the maximum plant height of $68 \mathrm{~cm}$ was at the right side of FVFS I. Minimum plant height was found at the right section of FVFS II and is about $12 \mathrm{~cm}$. At tier T2, maximum plant height of $57 \mathrm{~cm}$ and minimum plant height of $34 \mathrm{~cm}$ were found at the right side of FVFS I and left section of FVFS II respectively.

Similarly, at tier T3, maximum plant height of $62 \mathrm{~cm}$ and minimum plant height of $25 \mathrm{~cm}$ were found at right side of FVFS I and left section of FVFS II respectively.

From the graphs, it is clear that plant height was observed to be maximum in the right side tier T1 followed by right side tier T3 in FVFS I. This is highly correlated with the light intensity as maximum light intensity was observed in these tiers. This may be the reason for the increase in plant height. In FVFS II, the maximum plant height was observed at tier $\mathrm{T} 3$ of right section.

\section{Number of leaves}

At the end of $3^{\text {rd }}$ week after planting, the maximum number of leaves was found in the right side of FVFS I and it was 30 in number. Minimum number of leaves was found in the right section of FVFS II which was 4.

Considering $\mathrm{T} 1$ at the end of $3^{\text {rd }}$ week after planting, the maximum number of leaves was obtained at the right side of FVFS I and minimum was obtained at the right section of FVFS II and was found to be 17 and 4 respectively. At T2, 25 and 12 were the maximum and minimum number of leaves obtained from the right side of FVFS I and left section of FVFS II respectively. For T3, the maximum and minimum number of leaves 
was 30 and 5 and was found at the right side of FVFS I and left section of FVFS II. Variation in number of leaves with respect to time is shown in Figure 8.

From the Figure 8, it is clear that number of leaves was observed to be maximum in the right side tier $\mathrm{T} 3$ followed by right side tier $\mathrm{T} 1$ in FVFS I. This is correlated with the light intensity. The maximum light intensity was observed in these tiers. This may be the reason for the increase in number of leaves. In FVFS II, the maximum number of leaves was found at tier $\mathrm{T} 1$ of middle section. More light intensity was observed in this part of the structure and hence more number of leaves.

\section{Plant girth}

The plant girth was observed at the end of $3^{\text {rd }}$ week after planting. The maximum plant girth was observed in the right side of FVFS I and it was $1.7 \mathrm{~cm}$ and minimum was observed on the right section of FVFS II and was about 0.9 $\mathrm{cm}$. Among tier T1 of both structures, maximum plant girth was obtained at the left side of FVFS I and minimum from right section of FVFS II and the recordings was 1.6 $\mathrm{cm}$ and $0.9 \mathrm{~cm}$ respectively. At tier T2 maximum and minimum plant girth was obtained at the right hand side of FVFS I and left and middle sections of FVFS II. The measurements were $1.7 \mathrm{~cm}$ and $1.4 \mathrm{~cm}$ respectively. Considering T3, maximum plant girth was of $1.6 \mathrm{~cm}$ at the right side of FVFS I and minimum was about $0.9 \mathrm{~cm}$ at the left section of FVFS II. Variation in plant girth with time is as shown in the Figure 9. The study reveals that in the case of plant girth also, maximum girth for the plants was observed in right side of FVFS I in different tiers. The maximum was observed in tier T2. In FVFS II, the maximum plant girth was observed at tier $\mathrm{T} 2$ of right section and tier $\mathrm{T} 1$ of middle section. The maximum light intensity was observed at middle and right sections.

Apart from the climatic and biometric observation, the flowering pattern of the crops was noted. The plants from the FVFS I flowered early compared to those in FVFS II. Among the tiers in the FVFS I, plants from the top tier at right side (FRT1) of FVFS I showed better and early flowering.

The experiment results reveals that the biometric observations like plant height, number of leaves, plant girth were more in T1 at right side and followed by $\mathrm{T} 3$ at right side of FVFS I. The plant characteristics are correlated with the sun light. This is the reason for more growth in right side of FVFS I. The maximum plant height in FRT1and bottom tier at right side of FVFS I (FRT3) is $49 \mathrm{~cm}$ and $48 \mathrm{~cm}$ respectively. The number of leaves in FRT1 and FRT3 were 51 and 48. The plant girth measured in FRT1 was about $3 \mathrm{~cm}$ and $2.5 \mathrm{~cm}$ in FRT3. In FVFS II, the maximum plant growth was observed in $\mathrm{T} 1$ at middle section.

The observations revealed that there are only slight variations in the temperature between the fabricated and existing VFS For the cowpea. These slight variations in temperature may be due to the more reflected radiation from the ground surface to the FVFS I as there is a distance of $23 \mathrm{~cm}$ from the ground to the lowermost tiers which was less (about $9 \mathrm{~cm}$ ) in FVFS II. The heat of respiration liberated by the crops also has a small role on this observed variation. Orientation of the structure reflects on the variation of the temperature among different tiers.

Depending on the time of measurement, the maximum and minimum light intensities obtained in each tier varied. In the morning, it was observed that FRT3 got the maximum light intensity and at the same time, minimum light intensity was observed on EMT3. This is due to the orientation of the structure in east- 
west direction. In morning hours there was possibility of getting more solar radiation in left section of FVFS II, which was towards the east.

In the noon time, maximum and minimum light intensities were observed on FRT1 and EMT2 respectively. But in the evening maximum light intensity position was same as above. The minimum light intensity was observed at the same position as obtained in the morning. The observed changes may be due to the east-west orientation and direction of reflected solar radiation.

To compare the biometric observations for the trial with cowpea, the variations among crops on the same position were analyzed. Maximum plant height at the end of $3^{\text {rd }}$ week after planting was observed at tier $\mathrm{T} 1$ on right side of FVFS I. Minimum plant height was found at the tire T1 of right section of FVFS II. By considering all theT1 crops, the maximum plant height was at the right side of FVFS I and minimum plant height was found at right section of FVFS II. At tier T2, maximum plant height and minimum plant height were found at right side of FVFS I and left section of FVFS II respectively. Similarly, at tier T3, maximum plant height and minimum plant height was observed at right side of FVFS I and right section of FVFS II respectively. Maximum plant height was observed at the tiers that receives maximum light intensity.

At the end of 3rd week, the maximum number of leaves was observed in right side of FVFS. Minimum number of leaves was observed in left side of FVFS II. The analysis revealed that rate of increase in the number of leaves was more on the right side of the fabricated VFS followed by the left side of the same structure. More light intensity was observed in this part of the structure and hence more number of leaves. This is due to the orientation of the structure in east-west direction.

In the case of plant girth also, maximum girth for the plants was observed in right side of FVFS I. The maximum was observed in T2. The maximum light intensity was observed in these tiers. This may be the reason for the increase in plant girth. In FVFS II, the maximum plant girth was observed at tier T2 of right section and tier T1 of middle section. The maximum plant girth was observed at middle and right sections. This is due to the orientation of the structure in east-west direction. Climatic and biometric parameters are directly correlated with each other.

The analysis of trials revealed that fabricated vertical farming structure shows better performance in every aspect compared to the existing vertical farming structure. The reliability of results was found to be based on the flowering time and overall growth performance. Study recommended that usage of platform like structure with triangular cross section is more advantageous than structure with platform one over the other with PVC splits. The structure can also be recommended for urban areas as a substitute to the traditional farming practices. The structure can be adopted for limited land area conditions and for the soils having drought, salinity and toxicity problems. For the problematic soil, the VFS can be placed in the field itself and for the limited land areas it can be placed even in the balcony or rooftops of the building. The orientation of the VFS can be changed according to the climatic parameters.

\section{References}

Antalya, K. and Elinc, Z.K. 2013. Use of outdoor living walls in Mediterraneanlike climates. J. Fd. Agric. and Environ. 11(1): 687-692.

Badgley, C. and Perfecto, I. 2007. Can organic agriculture feed the world? Renewable Agriculture and Food Systems. 22(2): 
pp.80-85.

Bellows, A.C., Brown, K. and Smit, J. 2004. Health Benefits of Urban Agriculture. Community Food Security Coalition(CFSC), North American Initiative on Urban Agriculture committee.

Despommier, D. 2010. The Vertical Farm: Feeding the World in the 21st Century. New York: Martin's Press.

Garg, A. and Balodi, R. 2014. Recent Trends in Agriculture: Vertical Farming and Organic Farming. Adv Plants Agric Res. 1(4): 10-23.

Jegadeesh, M. and Verapandi, J. 2014. An Innovative Approach on Vertical Farming Techniques. Int J. Agric and environ Sci., 1(1): 2394-2568.

Kamonpatana, K. And Anuntavoranich, p. 2013. Vertical Farming Concept in Thailand: Important Decision Variables. Int J. Innovtv Res Sci. 2(12): 7654-7854.

Omrani, S., Garcia-Hansen, V., et al., (2017). On the effect of provision of balconies on natural ventilation and thermal comfort in high-rise residential buildings. Building and Environment 123: 504-516.

Philip, D., Nkonya, E., Pender, J. and Ayoola Oni, O. 2009. Constraints to Increasing
Agricultural Productivity in Nigeria: A Review, Nigeria Strategy Support Program (NSSP) Background Paper No. NSSP 006.

Sailor, D.J.1998. Simulations of annual degree day impacts of urban vegetative augmentation. Atmospheric Environment., 32(1): 43-52.

Salami, A., Kamara, A.B., and Brixiova, Z. 2010. Smallholder Agriculture in East Africa: Trends, Constraints and Opportunities. Working Paper No.105.

Shamshiri, R. R., Kalantari, F., et al., (2018). Advances in greenhouse automation and controlled environment agriculture: A transition to plant factories and urban agriculture. International Journal of Agricultural \& Biological Engineering 11(1): 1-22.

Sharanbir S. Grewal, P. S. G. 2011. Can cities become self-reliant in food?. Cities. 29(11): pp.1-11.

Valley, W. and Wittman, H. (2018). Beyond feeding the city: The multifunctionality of urban farming in Vancouver, BC. City, Culture and Society.

White, J. 2010. Sky-field: a Vertical Farming Solution for Urban New York. Architecture. Thesis, The Roger Williams University, New York. 138p.

\section{How to cite this article:}

Shaheemath Suhara, K. K. and Priya, G. N. 2019. Development and Performance Evaluation of a Vertical Farming Structure. Int.J.Curr.Microbiol.App.Sci. 8(12): 2630-2640. doi: https://doi.org/10.20546/ijcmas.2019.812.307 